\title{
An Application of Principal Agent Theory to Contractual Hiring Arrangements within Public Sector Organizations
}

\author{
Charlene M. L. Roach \\ The University of the West Indies, St. Augustine Campus, St. Augustine, Trinidad \& Tobago \\ Email: Charlene.Roach@sta.uwi.edu
}

Received 25 September 2015; accepted 30 January 2016; published 3 February 2016

Copyright (@ 2016 by author and Scientific Research Publishing Inc.

This work is licensed under the Creative Commons Attribution International License (CC BY). http://creativecommons.org/licenses/by/4.0/

(c) (i) Open Access

\section{Abstract}

This paper critically examines the application of principal agent theory to contractual hiring arrangements of employees in public sector organizations as a contemporary alternative recruitment strategy. Globally, developed and developing nations within the public sector are seeking ways where they can reduce public expenditure and debt while at the same time attempting to increase productivity and efficiency gains by using cost containment initiatives. Thus, private sector methods of outsourcing and contracting are identified as more economically feasible strategies given global recessions and other budgetary constraints within these public agencies. Hence, public management and administration scholars have alluded to the catchy phrase of "doing more with less" (see [1]). Thus, the paper from a theoretically exploratory perspective analyzes how principal agent theory can be applied to the hiring of contingent employees within this sector and the agency problems that may likely arise as a result of these arrangements and their probable economic implications for the said sector.

\section{Keywords}

Principal-Agent Theory, Agency Problems, Moral Hazard, Asymmetric Information, Adverse Selection

\section{Introduction}

A growing trend within public sector organizations is the use and application of contract employment as a parallel recruitment strategy to sustain and maintain their workforce. This paper examines the practice of contracting relationships within public sector organizations as it relates to the hiring of contingent employees within 
these establishments. Contingent employees may be defined as employees who are hired under contracts (i.e. contract employees/workers) that are temporary in nature. The terms and conditions of these contracts may vary from short term (between 1 to 6 months), medium term (6 months to 2 years) and long term (2 and more years to 5 or even more in some instances). They are different to the permanent public servants who also work within this sector who are entitled to pensions and other benefits of permanent workers of these agencies. The paper also applies principal agent theory as a conceptual framework to analyze the probable effects of agency problems that may develop as a result of contracting these contingent employees and the economic risks and implications that could be put forward. Agency theory has two underlying meanings which have been influenced from economics of organizational and institutional behaviour. Firstly, the Public Choice theorists believe that self-interests drive (rational utility maximizers) the behaviors of people and their organizations. Secondly, as a result of rational utility maximizers, all human activities can be determined by relationships between parties [2] [3].

Therefore, Principal Agent Theory with the implications of agency problems underscores the bedrock of analyses that can be generated in regard to contractual arrangements [4]-[6]. Such arrangements are ideally intended to be mutually beneficial to both principals and agents in spite of risks such as adverse selection, asymmetric information and moral hazard. Some economists have evaluated principal-agent theory to infer components of a "second-best contract". Here, a principle is established to determine how both parties - i.e. the principals (as employers) and the agent (as employees) —are able to share the outputs. The intent by the former is to glean the maximum amount of input not easily observed and exerted by the agents, see [4] [7]-[9] and others. Therefore, this theory is relevant for public sector organizations, practitioners and economic researchers as they explore the significance of agency problems in economic contract arrangements such as tangible incentives in light of their efficiencies.

\section{Definition of Principal Agent Theory (Model)}

The model will first be defined and then analyzed (i.e. in Section 2). There are components to the model and issues that arise that will be addressed in Section 3. These are important dimensions to consider as the paper will later examine its application (probable effects) in contract hiring relationships in public sector organizations in Section 4.

The Principal Agent Theory may be defined as a model "in which the leader who proposes the contract) is called the Principal and the follower (the party who just has to accept or reject the contract) is called the Agent. While this modeling choice makes things much simpler, the reader should keep in mind that actual bargaining procedures are likely to be much more complex" [10]. Thus, this model is intended to apply to any situation where there is a principal who defines a contract with an agent. The agent will then determine behaviors that are consistent with the desires of the principal [2]. Other researchers concede that an agency relationship is created when an individual or party who acts as a principal, instructs or deputizes to another person who acts as the agent, with the authority to act on his or her behalf [2] [11]-[14].

Thus, an agent can be defined as the person recruited by the principal to accomplish the latter's goals and objectives [11] [12] [14]. On the other hand, a principal can be an individual, party or body who acts in a consistent or cohesive manner (e.g. government agencies or public officials in the same), to recruit an agent or agents (e.g. contingent/contract employees) to achieve expected end results of the former.

Generally, a principal will select an agent (s) to execute tasks that may vary in specialized skills, task complexity, scope of the task and other requirements. These include aspects such as knowledge, qualifications, aptitudes, abilities and other characteristics given the nature of the jobs or tasks assigned (e.g. in the public sector they can be hired as information technology analysts, administrative and auxiliary staff, or human resources professionals). The agent (s) may also be required to execute the tasks within certain periods based on designated time lines, deadlines or time pressures.

\section{Components of the Model \& Probable Effects of Agency Problems within Contractual Arrangements within Public Sector Organizations}

Within the Principal Agent Theory (PAT) model there are components that may give rise to issues that require monitoring and in some instances, create concerns for principals and agents. These areas may affect all parties involved in positive and negative ways. Ultimately, they may even impact how actors manage their roles, beha- 
viors, expectations, interests, outcomes, information, resources and control mechanisms. These components are explained below and illustrate some of the challenges that may be experienced in government and public sector principal agent relationships.

The model informs that actors are perceived as rational utility maximizers [2]. This means that actors seek out their self-interests. In the context of public sector organizations, government and public officials may serve as principals and are likely to act in their interests by putting forward their priorities in light of their organizational goals and objectives. By so doing, government as principals may want to ensure that contract agreements reflect these priorities and expect their agents (contingent employees) to accomplish them within their contracts. Subsequently, contracts that are created are executed with the intent to accomplish public sector organizations' strategic goals, visions, purposes, objectives, agendas and mandates [3] [15] [16].

There is also an implicit understanding that agents (in this case contingent employees hired) will also seek to secure their interests in terms of the incentives (i.e. incentive schemes offered) they are offered. In the case of contracting of human resources for the public sector, agents as contract workers will expect competitive incentives written in the nature of their employment agreements by way of their terms and conditions. These may include examples such as salaries comparable to the private sector, benefits (allowances and perks), gratuities (longer termed contracts) and other marketable incentive schemes [17]. These schemes help to secure their commitment to the expected roles outlined and outcomes sought by principals for the public sector organizations (e.g. senior public administrative officials), (e.g. [3] [15] [16]. Thus, a symbiotic relationship evolves where both parties" interests should have alignment and the development as noted in the Introduction of a "second-best contract" see [4] [7]-[9] and others.

The aspect of contractual incentive design in principal-agent relationships is extremely important and is a responsibility for principals. In fact, principals need to ensure as rational utility maximizers that agents are provided with comparable and competitive compensation and other incentives in their agreements [4] [17] [18]. These will enhance agents' acceptance of their terms and conditions at the signing off of these agreements and their motivation to commit to expected roles after the contracts have been accepted. Hence, contracts within the public sector context for contingent employees (as agents) should outline services to be rendered, tasks to be accomplished and deadlines required, performance evaluation criteria that will be used, measurement of inputs and outcomes and details of salary and other compensation schedules. However, these may be difficult to apply in all principal-agent relationships in light of information asymmetry and goal divergence issues [6] [19].

Information asymmetry explains a situation where parties may have divergent information about a transaction [6] [17]. In other words, information may differ in many situations for principals and agents [10]. As a result, it may lead to increasing transaction costs where efforts may be used to acquire data, enhance its accuracy and or evaluate as needed. Some scholars allude to the fact that principals may be ignorant about the nature of services or products and the quality of performance of agents such as within a public sector organizational context (e.g. [6] [19] [10]). Herbert Simon's classic terminology of bounded rationality applies to issues of information asymmetry where principals may expend resources in light of their uncertainty and bounded rationality to track agents' performance, behaviors and other activities. Yet, Williamson infers from Herbert Simon's bounded rationality that decision makers such as public sector officials as principals may be forced to satisfice given their cognitive limitations of information, lack of complete monitoring mechanisms and other resources as per agents' activities and may have to weigh the marginal costs against the marginal benefits derived from their monitoring strategies [14].

Goal divergence is another component and issue that emerge within the PAT model. It highlights a concern of the alignment of both parties' interests. In essence, principals (e.g. public sector officials) and agents (e.g. contingent employees) may share different interests. In a principal-agent scenario, the principal recruits the agent to achieve the principal's objectives. As explained above, both parties as rational utility maximizers have separate interests in mind. However, the model informs that principals should attempt to align the agents' interests to their interests by the compelling incentives schemes provided. Public sector organizations unlike their private sector counterparts are constrained financially to offer the most attractive and compelling compensation and other benefits to recruit and select the best and brightest in terms of their permanent workforce and even contracted/contingent employees based on market demands and trends for the same. It is noted in the literature that public sector organizations lag behind in their compensation and benefits versus the private sector (e.g. [1]). Yet, at another level, there are other interests that agents may have in mind to accomplish that may not be consistent with the principals' primary outlined expectations and outcomes sought. The agents' secondary objectives may 
lead to goal divergence and to behaviors that will divert attention away from principals’ primary objectives and goals from being achieved [6] [11] [12] [14].

As a consequence of goal divergence and information asymmetry, moral hazard may develop in principalagent relationships. Simply put, it describes a situation where one actor (principal or agent) is motivated to behave in a manner in which one party benefits (i.e. self-seeking) at the expense of the other party. Typically, an agent may engage in shirking behaviors which are self-serving [5]. By so doing, they engage in non-compliance activities which divert their attentions away from achieving the principals' primary objectives outlined and expected, in order to secure their secondary interests. Within public sector organizations, agents (as contingent employees) may deviate from their contract obligations to engage in behaviors that may be described as opportunistic leading to breaches in the terms and conditions of their employment contracts [6] [19].

A corollary to moral hazard and information asymmetry is adverse selection. This occurs when a principal or agent may use their private information at the expense of the party who may be less informed [6]. Some scholars assert that it could be a type of market failure as a result of information asymmetry [6] [10] [14]. According to Moe, it is the "unobservability of the information, beliefs, and values on which the decisions of others are based" [2]. The risk and challenge exist that a principal once he/she recruits an agent, that there is no certainty that the principal's primary interests will be accomplished by the said agent. Rather, an agent may place his/her interests as priority.

The dimensions of the PAT model provide insights into the characteristics of the nature of principal-agent relationships. Serious issues emerge and these can be more challenging to manage in principal-agent relationships within public sector organizations [3] [6] [15] [16] [19] [20]. For instance, government or public officials within agencies serve as the principals with institutional decision making powers. They are driven as rational utility maximizers to accomplish their strategic organizational priorities such as will be reflected within their contract employment arrangements.

\section{Economic Implications \& Recommendations for Public Sector Organizations}

The paper presents some economic implications and recommendations for public sector organizations to consider in their application of contractual hiring arrangements within their sector. One economic implication is that such arrangements pose risks as they present serious technical challenges from a theoretical perspective that present no easy solutions to be put forward. Economic theorists have described agency problems as providing "intractable solutions" and presenting "mathematical characterization of solutions to the PAT model as creating more difficulties". Others assert that "quantitative solutions are not as readily available from implicit equations of sharing rules". Thus, therein highlights a few of the challenges and economic risks posed by its application to contractual hiring arrangements within public sector organizations [4] [10] [21].

On a practical side to note, PAT arrangements in contractual hiring relationships may not serve public sector organizations in their best economic interests. This is especially so as a long term strategy. Hence, this practice may in fact minimize its potential economic benefits for the public sector in terms of cost containment priorities, initiatives and efforts. It may in fact increase transaction and sunk costs associated with the hiring and maintenance of these contingent employees alongside permanent public servants in the long term. Agency problems also run the risk of incurring higher transaction costs in the creation of incentives for agents hired (contingent employees), monitoring controls and other resources to manage moral hazard and other opportunistic behaviors that may arise within the sector as a result of contractual hiring of contingent employees in the public sector. Scholars have referred to the need as a result of moral hazard to implement a requirement of performance monitoring which create exorbitant costs to principals and agents alike and introduces according to Gauld, "goal-displacing behavior on the behalf of agents when they place a disproportionate emphasis on work that is specifically subject to monitoring" [3].

Another economic impact that agency theory may likely introduce to the public sector as a unique complication is that of policy refinement. In most cases within the public sector policy refinement occurs at the implementation stage and is commonly performed by agents and not the reverse by principals as expected. A corollary to this is that most public sector organizations experience fragmentation and diffusion of tasks and objectives, red tape, multiple principals (e.g. government appointed officials and career bureaucrats/administrators), principals doubling as agents (e.g. some contingent employees also serve as permanent public servants in instances where they may take temporary leave from permanent positions to serve on contract for specific periods for spe- 
cial roles/projects as contingent employees). By so doing, these conflicting tasks, roles and objectives may create more negative economic impacts for this sector in terms of policy refinement and its economic repercussions in the long term.

Furthermore, these proposed economic impacts reinforce the need for studies within the public sector to justify the economic sustainability of having parallel systems of contingent hiring of employees and the recruitment and retention of permanent public servants. Additionally, the public sector is not guaranteed to retain contingent employees' intellectual capital and knowledge management systems. These risks may incur long term economic constraints for the public sector in strengthening its institutional framework (e.g. knowledge management and other resources) such as those who are contingent by the nature of their contract agreements.

Moreover, unlike the private sector, the public sector differs since public sector organizations fit within the framework of political institutions (i.e. public bureaucracies with governmental/political influences), where the distribution of citizens' interests and preferences may be distorted. The public sector is also prone to fragmentations, parochialism, and mobilization of bias by rival and special interests mixed in with a concern for the public at large or for society's well-being [3] [6] [15] [16] [19] [20]. Frequently, miscommunications, goal divergence, information asymmetry, adverse selection and other issues may surface that make principal-agent relationships challenging to manage and to create adequate control mechanisms within this sector for long term economic sustainability. A further challenge can be put forward as an economic implication as reinforced by economists in asking how then given such risks can optimal contracts be determined in realistic agency arrangements such as within the context of public sector organizations? [4]

In light of the discussion, there are no easy solutions or quick fixes identified at a theoretical level or in practice. In essence, it is suggested that some possible economic solutions may lead to paradoxes which invalidate them theoretically such as first order approaches and minimum payments in PAT relationships [4] [22]. Another recommendation presented in the literature for consideration is the use or application of non-linear compensation contracts. These types of contracts include but are not limited to what occurs in the private sector in regards to stock options, competency based pay, bonuses and merit awards or pay for performance packages. There may be limitations since they are applied at a strategic managerial level for executives, directors and top officials who lead in companies [4] [5].

Given this approach within the public sector, comparable incentives may be considered where they could be feasible for that sector and its cultural practices. Examples include merit pay and pay-for-performance schemes. On the other side, there is an additional challenge for the public sector with constraints based on cost containment and budgetary limitations [1]. Public sector organizations may also be challenged with the existence of parallel systems within their recruitment and compensation of permanent public servants hired within these agencies alongside contingent employees. This introduces paradoxes to apply non-linear compensation packages. Further, the public sector is not oriented like the private sector with bottom line objectives and tangible incentives that could be used to induce contingent employees to perform better in their work agreements. Thus, economists warn against inherent limitations theoretically within non-linear contracts since they are intended for managerial and supervisory levels [4] [5] [17].

In closing, these recommendations and implications may present risks and limitations both theoretically and practically. They are not fully guaranteed to execute in light of "efficiency in exerting adequate effort (i.e. effort extraction)" and mitigating "risk-sharing areas" which may still be open for theoretical debate and inquiry [4] [21].

\section{Conclusion}

This paper presents an exploratory discussion of the theoretical application of the PAT model to analyze the possible impacts of agency problems that may develop over time as a consequence of contractual hiring of contingent employees in public sector organizations. It briefly examines some of the economic impacts and implications that could be put forward. It does not provide a specific example of public organizations but illustrates the unique aspects of this sector that make contract hiring of contingent employees a risky practice for long term sustainability using the lens of the PAT model. Recommendations and their implications are highlighted for further consideration. It poses interesting economic questions and concerns for future research and examination.

\section{References}

[1] Osborne, D. and Gaebler, T. (1992) Reinventing Government: How the Entrepreneurial Spirit Is Transforming the Public Sector. Addison-Wesley Publishing Company Inc., Reading. 
[2] Moe, T.M. (1984) The New Economics of Organization. American Journal of Political Science, 28, 737-777. http://dx.doi.org/10.2307/2110997

[3] Gauld, R. (2007) Principal-Agent Theory and Organisational Change: Lessons from New Zealand Health Information Management. Policy Studies, 28, 17-34. http://dx.doi.org/10.1080/01442870601121395

[4] Gutiérrez, Ó. (2012) On the Consistency of the First-Order Approach to Principal-Agent Problems. Theoretical Economics Letters, 2, 157-161. http://dx.doi.org/10.4236/tel.2012.22028

[5] Jewitt, I., Kadan, O. and Swinkels, J. (2008) Moral Hazard with Bounded Payments. Journal of Economic Theory, 143, 59-82. http://dx.doi.org/10.1016/j.jet.2007.12.004

[6] Kauppi, K. and van Raay̆, E.M. (2014) Opportunism and Honest Incompetence in Public Procurement. Journal of Public Administration Research and Theory, 25, 953-979.

[7] Mirrlees, J. (1976) The Optimal Structure of Incentives and Authority within an Organization. Bell Journal of Economics, 7, 105-131. http://dx.doi.org/10.2307/3003192

[8] Ross, S. (1973) The Economic Theory of Agency: The Principal’s Problem. American Economic Review, 63, $134-139$.

[9] Holmstrom, B. (1979) Moral Hazard and Observability. Bell Journal of Economics, 10, 74-91. http://dx.doi.org/10.2307/3003320

[10] Whitford, A.B., Bottom, W.P. and Miller, G.J. (2013) The (Negligible) Benefit of Moving First: Efficiency and Equity in Principal-Agent Negotiations. Group Decision Negot, 22, 499-518. http://dx.doi.org/10.1007/s10726-011-9280-4

[11] Rees, R. (1985) The Theory of Principal and Agent Part 1. Bulletin of Economic Research, 37, 3-26. http://dx.doi.org/10.1111/j.1467-8586.1985.tb00179.x

[12] Rees, R. (1985) The Theory of Principal and Agent Part 2. Bulletin of Economic Research, 37, 75-95. http://dx.doi.org/10.1111/j.1467-8586.1985.tb00185.x

[13] Walker, P. (2007) Contracts, Entrepreneurs, Market Creation and Judgment: The Contemporary Mainstream Theory of the Firm in Perspective. Journal of Economic Surveys, 29, 317-338. http://dx.doi.org/10.1111/joes.12058

[14] Williamson, O.E. (2000) The New Institutional Economics: Taking Stock, Looking Ahead. Journal of Economic Literature, 38, 595-613. http://dx.doi.org/10.1257/jel.38.3.595

[15] Lavoie, J.A. and Dwyer, J. (2010) Analysing Contractual Environments: Lessons for Indigenous Health in Canada, Australia and New Zealand. Public Administration, 88, 665-679. http://dx.doi.org/10.1111/j.1467-9299.2009.01784.x

[16] Ward, R.C. (2007) The Outsourcing of Public Library Management: An Analysis of the Application of New Public Management Theories from the Principal-Agent Perspective. Administration and Society, 36, 627-648. http://dx.doi.org/10.1177/0095399706293982

[17] Marvel, M.K. and Marvel, H.P. (2009) Shaping the Provision of Outsourced Public Services: Incentive Efficacy and Service Delivery. Public Performance and Management Review, 33, 183-213. http://dx.doi.org/10.2753/PMR1530-9576330201

[18] Prendergast, C. (1999) The Provision of Incentives in Firms. Journal of Economic Literature, 37, 7-63. http://dx.doi.org/10.1257/jel.37.1.7

[19] Van Slyke, D.M. and Roch, C.H. (2004) What Do They Know, and Whom Do They Hold Accountable? Citizens in the Government-Nonprofit Contracting Relationship. Journal of Public Administration Research and Theory, 14, 191-209. http://dx.doi.org/10.1093/jopart/muh013

[20] Vining, A.R., Boardman, A.E. and Moore, M.A. (2014) The Theory and Evidence Pertaining to Local Government Mixed Enterprises. Annals of Public and Cooperative Economics, 85, 53-86. http://dx.doi.org/10.1111/apce.12029

[21] Haubrich, J. (1994) Risk Aversion, Performance Pay and the Principal-Agent Problem. Journal of Political Economy, 102, 258-276. http://dx.doi.org/10.1086/261931

[22] LiCalzi, M. and Spaeter, S. (2003) Distributions for the First- Order Approach to Principal-Agent Problems. Economic Theory, 21, 167-173. http://dx.doi.org/10.1007/s00199-001-0250-y 